\title{
Dietary Carbohydrate and Nocturnal Sleep Duration in Relation to Children's BMI: Findings from the IDEFICS Study in Eight European Countries
}

\author{
Monica Hunsberger ${ }^{1, *}$, Kirsten Mehlig ${ }^{1}$, Claudia Börnhorst ${ }^{2}$, Antje Hebestreit ${ }^{2}$, Luis Moreno ${ }^{3}$, \\ Toomas Veidebaum ${ }^{4}$, Yiannis Kourides ${ }^{5}$, Alfonso Siani ${ }^{6}$, Dénes Molnar ${ }^{7}$, Isabelle Sioen ${ }^{8,9}$ and \\ Lauren Lissner ${ }^{1}$ \\ Received: 7 August 2015; Accepted: 1 December 2015; Published: 8 December 2015 \\ 1 Section for Epidemiology and Social Medicine, University of Gothenburg, P.O. Box 453, 40530 Gothenburg, \\ Sweden; kirsten.mehlig@gu.se (K.M.); lauren.lissner@gu.se (L.L.) \\ 2 Leibniz Institute for Prevention Research and Epidemiology-BIPS GmbH, Achterstrasse 30, \\ D-28359 Bremen, Germany; boern@bips.uni-bremen.de (C.B.); hebestr@bips.uni-bremen.de (A.H.) \\ 3 Growth, Exercise, Nutrition, and Development (GENUD) research group, University of Zaragoza, \\ Domingo Miral, 50009 Zaragoza, Spain; lmoreno@unizar.es \\ 4 National Institute for Health Development, P.O. Box 3012, 10504 Tallinn, Estonia; \\ toomas.veidebaum@tai.ee \\ 5 Research and Education Institute of Child Health, 138 Limassol Ave, \#205, 2015, Strovolos 510903, Cyprus; \\ kourides@cytanet.com.cy \\ 6 Institute for Food Sciences, Unit of Epidemiology and Population Genetics, National Research Council, \\ Via Roma 64, 83100 Avellino, Italy; asiani@isa.cnr.it \\ 7 Department of Paediatrics, Medical Faculty, University of Pécs, Jozsef A.u., 7 H-1062 Budapest, Hungary; \\ molnar.denes@pte.hu \\ 8 Department of Public Health, Ghent University, 4K3, De Pintelaan 185, 9000 Ghent, Belgium; \\ isabelle.sioen@ugent.be \\ 9 Research Foundation-Flanders, Egmonstraat 5, B-1000 Brussels, Belgium \\ * Correspondence: monica.hunsberger@gu.se; Tel./Fax: +46-0-7033-82411
}

\begin{abstract}
Previous research has found an association between being overweight and short sleep duration. We hypothesized that this association could be modified by a high carbohydrate (HC) diet and that the timing and type (starch or sugar) of intake may be an important factor in this context. Participants in the prospective, eight-country European study IDEFICS were recruited from September 2007 to June 2008, when they were aged two to nine years. Data on lifestyle, dietary intake and anthropometry were collected on two occasions. This study included 5944 children at baseline and 4301 at two-year follow-up. For each meal occasion (morning, midday, and evening), starch in grams and sugar in grams were divided by total energy intake (EI), and quartiles calculated. HC-starch and HC-sugar intake categories were defined as the highest quartile for each meal occasion. In a mutually adjusted linear regression model, short sleep duration as well as HC-starch in the morning were positively associated with body mass index (BMI) z-scores at baseline. HC-starch at midday was positively associated with body mass index (BMI) z-scores in children with short sleep duration, and negatively associated with BMI z-scores in those with normal sleep. After adjustment for baseline BMI z-scores, associations between total HC from starch or sugar and high BMI z-scores at two-year follow-up did not persist. Our observations offer a perspective on optimal timing for macronutrient consumption, which is known to be influenced by circadian rhythms. Reduced carbohydrate intake, especially during morning and midday meals, and following nocturnal sleep duration recommendations are two modifiable factors that may protect children from being overweight in the future.
\end{abstract}

Keywords: proportion carbohydrate intake at main meals; starch; sugar; childhood overweight; nocturnal sleep duration; breakfast consumption 


\section{Introduction}

Childhood obesity is a serious threat to public health due to long-term consequences, including chronic disease in early adulthood [1]. Overweight and obesity are believed to be preventable conditions, although the issue of effective interventions for primary prevention is not well understood [2] and increased knowledge of modifiable risk factors is needed [3].

Previous investigations have shown that reduced sleep duration is associated with overweight in children and adolescents [4-6]. Nielsen et al. (2011) report on eight prospective cohort studies of children, all of which confirmed a significant inverse association between hours spent sleeping and future weight gain or development of obesity [4]. Findings from a Belgian longitudinal study confirmed that short sleep duration is associated with central adiposity [7]. Additionally, findings from our own cohort, the Identification and prevention of Dietary- and lifestyle-induced health EFfects In Children and infantS (IDEFICS) study, indicated that sleep duration and overweight were associated cross-sectionally, but this association was no longer observed after adjustment for other behavioral factors and for parental education [8].

Carbohydrate, i.e., digestible starch and sugar, is likely to play a significant role in energy balance since it is the major macronutrient impacting blood sugar levels. Low carbohydrate intake is generally defined as $<130 \mathrm{~g}$ / day or $<26 \%$ of total energy intake (EI), while $26 \%-45 \%$ of EI from carbohydrates is considered to be moderate carbohydrate intake [9]. A carbohydrate proportion exceeding $45 \% \mathrm{EI}$ is considered to be moderately high and $>60 \%$ of EI from carbohydrates is considered to be high, although there is no clear established cut-off [10].

Relatively few studies have investigated the relationship between dietary carbohydrate intake and energy balance in children. However, the Feeding Infants and Toddlers Study (FITS), conducted in the USA, found that toddlers often have low intakes of fruits and green or yellow vegetables, consuming instead a high amount of starchy foods from grains. The authors highlighted this as a potential focus area for early overweight prevention efforts [11]. A study of Malaysian children found that the percentage of total EI represented by carbohydrates was significantly higher in overweight/obese children, compared with normal-weight children [12], suggesting that the proportion of EI from carbohydrates may play a role in childhood obesity.

Breakfast is often high in carbohydrate from both starch and sugar. Furthermore, the relationship between breakfast consumption patterns and overweight is not clear. Eating breakfast has long been portrayed as important, possibly enabling control of overconsumption later in the day. Several studies of breakfast-skipping behavior across European countries have shown that children who eat breakfast have a lower BMI, compared with children who do not [13-16]. However, a 2010 systematic review reported that breakfast consumption is associated with increased body weight in European children and adolescents in observational studies but that causality was not demonstrated [17]. Brown et al. (2013) concurred, stating that the proposed effect of consuming breakfast on obesity is not supported by scientific findings [18].

Therefore, the aims of this study were to examine whether high intake of carbohydrate modifies the association between short sleep duration and overweight, whether intake of starch and sugar differ in this regard, whether the timing (morning, midday, and evening) of carbohydrate intake is significant, and whether breakfast consumption, regardless of macronutrient composition, minimizes the risk of overweight in a mutually adjusted model (see Figure 1). The study was conducted on a geographically dispersed European sample participating in IDEFICS $[19,20]$. 


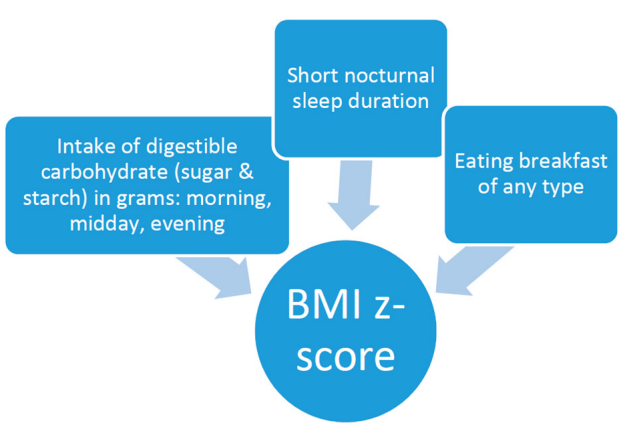

Figure 1. Factors investigated with body mass index (BMI) z-scores. Eating breakfast has a negligible relationship with carbohydrate (sugar and starch) intake during meals. Correlations range from -0.11 (evening sugar) to 0.13 (morning sugar).

\section{Methods}

\subsection{Participants}

IDEFICS is a prospective cohort study with an embedded intervention, including eight centers in Europe (Belgium, Cyprus, Estonia, Germany, Hungary, Italy, Spain and Sweden). From September 2007 to June 2008, 16,228 children aged two to nine years underwent the baseline investigation, providing lifestyle and dietary pattern information, anthropometrics and biological samples. Following recruitment, a community intervention with six key health messages was undertaken, including: (1) increasing daily physical activity; (2) decreasing daily screen time; (3) increasing fruit and vegetable intake; (4) drinking more water; (5) getting adequate sleep; and (6) being together with family. From September 2009 to March 2010, the children participated in a follow-up examination.

During the baseline and follow-up examinations, parents or legal guardians provided written informed consent for all examinations and the collection of biological samples, as well for analysis and storage of personal data and collected samples. Survey centers in the eight countries collected data according to standardized operating procedures and adherence to a predefined protocol. All questionnaires were translated from English into the respective national language and then back-translated into English at the respective study centers, in order to ensure accuracy of translations. Detailed information on the study procedures is available in [19-21].

\subsection{Assessment Of Main Exposures: High Carbohydrate Intake and Sleep Duration}

Dietary intake was assessed by standardized 24-h dietary recalls (24-h), based on the responses of parents or guardians (hereafter called "parents") of participating children to the Self-Administered Children and Infant Nutrition Assessment (SACINA). This computer-based instrument, previously created for the Healthy Lifestyle in Europe by Nutrition in Adolescence (HELENA) study, was developed for IDEFICS based on Young Adolescents' Nutrition Assessment on Computer (YANA-C) software [22,23]. The dietary recall part of the Self Administered Children and Infant Assessment (SACINA) instrument presents, in an interactive menu, country-specific food items with photographs of different portion sizes for the most common items, as well as probing questions regarding usual combinations of foods such as cereal and milk. The information collected through the SACINA was linked to Food Composition Tables (FCT) in order to calculate nutrient intake. The respective national FCT was used in each country except Hungary, where the German FCT was used. Nutrients are presented in standard units, grams and kilocalories (kcal), based on a standard FCT [24].

Data on diet and sleep were collected on all days of the week, including weekends. Most parents completed one 24-h recall for their child, while a subset completed more than one recall. As parents were not able to report on meals consumed at schools or kindergartens, an on-site school meal assessment, using a predefined observation-recording template with standard portions, was carried 
out by a teacher or school employee. A complete 24-h recall included everything the children ate or drank during their waking hours during one day. The 24-h recall allows for the calculation of energy intake, the proportion of intake from each of the macronutrients, the proportion of carbohydrate kcal from sugar and starch and hours of nocturnal sleep, hereby referred to as sleep. We defined short sleep duration as less than $10 \mathrm{~h}$, based on sleep recommendations for children [25].

We restricted the present sample to interviews recalling intake Monday through Thursday, as a previous investigation on the same sample indicated that dietary intake on Friday lies between weekday and weekend intake $[8,26]$. Therefore, to minimize heterogeneity we classified Friday as a weekend day and excluded them. In cases with more than one dietary recall, only the first complete weekday record of dietary intake was included in the analysis.

The SACINA instrument is structured around six meals without time parameters: breakfast, mid-morning snack, lunch, afternoon snack, evening meal and evening snack. If an additional snack was indicated in the interview, it was added to a previous snack in order to account for all EI. However, five was the median number of meals consumed and only $20 \%$ of children exceeded this number of meals. Eating breakfast was recorded as yes or no, based on the 24-h recall.

Importantly, as under- and over-reporting of dietary intake is a common problem, we examined total daily EI by comparing EI to the basal metabolic rate estimated by the age- and gender-specific Schofield equation [27]. Using the widely-acknowledged Goldberg cut-offs, we classified 254 (3.43\%) as over-reporters and $701(9.45 \%)$ as under-reporters and removed these 955 subjects from the analysis [28]. The prevalence of under- and over-reporting is not equally distributed across the countries. Under-reporting ranged from $1.1 \%$ in Spain to $18.44 \%$ in Cyprus, while over-reporting was most prevalent in Italy (5.6\%) and lowest in Sweden $(1.1 \%)$. When the under- and over-reporting subjects were excluded, Cyprus lost 19.6\%, Hungary 19.4\%, Germany $14.5 \%$, Belgium $13.0 \%$, Italy $11.5 \%$, Estonia $11.2 \%$, Spain $5.2 \%$ and Sweden $4.8 \%$. An additional 107 cases were excluded because macronutrient components did not equal total EI, a result of missing data in the national FCTs.

For each meal occasion (morning, midday, and evening), starch in grams and sugar in grams were divided by total energy intake (e.g., the sum of sugar in grams for breakfast and morning snack/total daily EI). Then, HC intake for starch and sugar on each occasion was defined by assigning those in the highest quartile to the HC-starch and HC-sugar intake categories. Average intakes of starch during morning, midday, and evening meals were 50, 115, and $61 \mathrm{~g}$, respectively. Similarly, average intakes of sugar were 64,70 , and $53 \mathrm{~g}$, for the three meal periods. When describing total carbohydrate intake for the day, percentage of total energy from both carbohydrate sources was used.

\subsection{Anthropometry and Body Mass Index (BMI)}

Anthropometric data were collected at each participating survey center, according to a standard protocol. Body height was measured without shoes by trained research staff using a portable stadiometer (SECA 225). Body weight was measured with an electronic scale (TANITA BC 420 SMA), with subjects wearing light clothing. BMI-z-scores and BMI categories were calculated according to the criteria of the International Obesity Task Force (IOTF) [29]. The same procedure was followed at both examinations (baseline 2007/2008 and follow-up 2009/2010) and inter-observer reliability was assessed at each survey center [30].

\subsection{Other Factors}

Age, sex, highest household parental education level and survey country were included in the multivariable model. Data on parental factors were collected by a standardized parental questionnaire. Age was examined as a continuous variable. Household parental education level was categorized according to the International Standard Classification of Education (ISCED) and the original six ISCED levels were then combined into two levels [31]. ISCED levels 0-4 constitute "not high" education while levels 5 and 6 are defined as high. Moreover, we controlled for intervention 
when examining BMI z-scores at follow-up, as children in the intervention had been exposed to instructions to get adequate sleep.

After limiting our sample to the first weekday recall, excluding cases with missing information about school meals or other meals outside of parental control and incomplete recalls, data from 7416 children were available. After excluding over- and under-reporters and children with incomplete sleep data, the baseline sample size was reduced to 5944. The longitudinal sample was further reduced to 4301 as some children were lost to follow-up (see Figure 2).

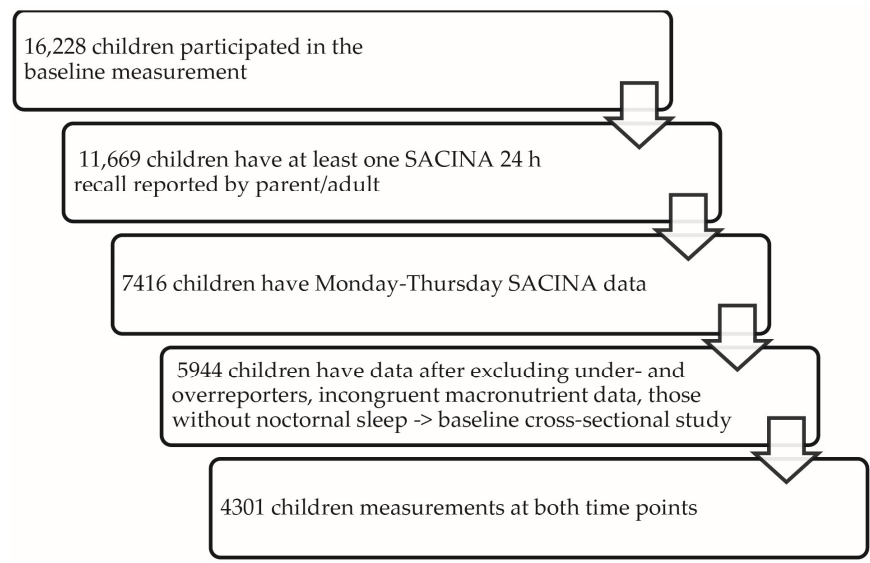

Figure 2. Study participants.

\subsection{Statistical Analysis}

BMI z-scores and dietary exposures are presented by short sleep duration at baseline. T-tests and regression equations controlling for country and age were used to make comparisons between short sleepers and "not-short" sleepers, presented with group means, regression coefficients and 95\% confidence intervals. Linear regression was used for analysis of continuous variables (BMI-z-score, energy kcals/day, starch in grams, sugar in grams and macronutrient proportions) and logistic regression for binary outcomes (high starch and high sugar) at each time-point, eating breakfast (yes or no), high household parental education level); the respective regression coefficients are reported.

At baseline, we used a multivariable regression model to assess the association between BMI z-scores and short sleep duration $(<10 \mathrm{~h})$ and high intake of carbohydrate from starch and sugar at three different time-points (morning, midday, evening), while controlling for age, sex and parental education, and including country as a random intercept.

The same baseline variables were included in our prediction of BMI z-scores at two-year follow-up, in which we further controlled for BMI z-scores at baseline and exposure to the IDEFICS intervention, as mentioned above. Cross-sectionally at baseline, we assessed how being in the highest quartile of carbohydrate for starch or sugar modified the association between short sleep duration and BMI z-scores by introducing six product terms, i.e., the dichotomized sleep variable multiplied by high starch and sugar intake at three time-points (morning, midday, evening). We further controlled for age, sex and parental education and included country as a random intercept.

We checked for multicollinearity between predictors and confounders included in the model by estimating the variance inflation factor (VIF), finding that none exceeded 2.0.

The significance level was set at $\alpha=0.05$ for all analyses (2-sided tests). Statistical analyses were carried out with Stata Intercool 11.2, StataCorp LP, 4905 Lakeway Drive, College Station, TX, USA.

\subsection{Ethics Statement}

We certify that all applicable institutional and governmental regulations concerning the ethical use of human volunteers were followed during this research and that the IDEFICS study passed 
the Ethics Review process of the Sixth Framework Programme (FP6) of the European Commission. Ethical approval was obtained from the relevant local or national ethics committees by each of the eight study centers: the Ethics Committee of the University Hospital Ghent (Belgium); the National Bioethics Committee of Cyprus (Cyprus); the Tallinn Medical Research Ethics Committee of the National Institutes for Health Development (Estonia); the Ethics Committee of the University of Bremen (Germany); the Scientific and Research Ethics Committee of the Medical Research Council, Budapest (Hungary); the Ethics Committee of the Health Office, Avellino (Italy); the Ethics Committee for Clinical Research Aragon (Spain); and the Regional Ethical Review Board of Gothenburg (Sweden). All parents of the participating children gave written informed consent to data collection, examinations, collection of samples, subsequent analysis and storage of personal data and collected samples. Additionally, each child gave verbal consent after being verbally informed in simple terms, due their young age, about the study by a study nurse. This consent process was not further documented, but it was subject to central and local training and quality control procedures. Study participants and their parents could consent to single components of the study, while abstaining from others. All procedures were approved by the above-mentioned Ethics Committees.

\section{Results}

The study population at baseline is shown in Table 1. This study has an almost equal distribution of boys and girls in all countries and a mean age of 6.1 years at baseline. There was large inter-country variability in the proportion of children with a high intake of carbohydrate from starch and sugar respectively: generally low in Spain and high in Hungary and Italy. Short sleep duration also varied by survey country, with the lowest proportion of children categorized as short sleepers in Belgium $(2.5 \%)$ and the highest in Estonia (69.6\%).

Subjects who reportedly consumed breakfast consumed more morning sugar ( $33 \mathrm{~g}$ vs. $25 \mathrm{~g}$ ), morning starch ( $26 \mathrm{~g}$ vs. $20 \mathrm{~g}$ ), midday starch $(56 \mathrm{~g}$ vs. $52 \mathrm{~g}$ ) and evening starch ( $28 \mathrm{~g}$ vs. $26 \mathrm{~g})$ than those reporting no breakfast. Breakfast-eaters reported consuming less midday sugar ( $34 \mathrm{~g} v \mathrm{~s} .37 \mathrm{~g}$ ) and less evening sugar ( $22 \mathrm{~g}$ vs. $29 \mathrm{~g}$ ) than those reporting no breakfast (results not shown in tables).

In Table 2, we show cross-sectional differences in a range of baseline variables by sleep duration, adjusted for age and country at baseline. Short sleepers had significantly higher BMI $\mathrm{z}$-scores than those sleeping $10 \mathrm{~h}$ or more. Raw numbers indicated that short sleep duration was associated with lower probability of high starch intake in the morning but the association was reversed when adjusted for age and survey country, as indicated by a positive beta-coefficient. Furthermore, regression analyses showed that short sleep was associated with less sugar intake at midday but more sugar intake in the evening. The cross-sectional analysis conducted at baseline was repeated cross-sectionally at follow-up without notable difference and is therefore not shown.

Table 3 shows mutually adjusted multivariable linear regression of BMI z-scores at baseline as a function of exposure to high starch and sugar intake at three time-points (morning, midday, and evening) and short sleep duration (referent group "normal to long sleep"), with adjustment for age, sex, high parental education level and survey country. At baseline, a significant positive association was observed between higher BMI z-scores and short sleep duration, HC intake from morning starch and higher values of total EI. A significant inverse association with BMI z-scores was observed for eating breakfast, high parental education level and HC evening starch. When it came to prediction of two-year BMI z-scores, protective associations with both breakfast consumption and high household parental education level were found. Characteristics associated with increased BMI z-scores included high intake of carbohydrate from morning starch and high intake of overall energy in a model mutually adjusted for age, sex, parental education, survey country and intervention vs. control study region but unadjusted for baseline BMI z-scores. When baseline BMI z-scores were included in the model, only high parental education was inversely associated with increasing BMI $\mathrm{z}$-scores. HC from starch in the morning approaches significance (Regression coefficient $=0.05$, $p=0.060 ; 95 \% \mathrm{CI}=-0.001 ; 0.095)$. 
Table 1. Characteristics of the study sample and distribution of covariates by country at baseline 2007/2008.

\begin{tabular}{|c|c|c|c|c|c|c|c|c|c|}
\hline & Belgium & Cyprus & Estonia & Germany & Hungary & Italy & Spain & Sweden & All \\
\hline Variable & $n=277$ & $n=699$ & $n=621$ & $n=1181$ & $n=519$ & $n=1367$ & $n=411$ & $n=869$ & $n=5944$ \\
\hline Intervention area, $n(\%) v s$. control & $164(59.2)$ & $268(38.3)$ & $241(38.8)$ & $652(55.2)$ & $272(52.4)$ & $794(58.1)$ & $368(89.5)$ & $394(45.3)$ & $3153(53.1)$ \\
\hline Mean age (SD) & $5.5(1.6)$ & $6.2(1.4)$ & $6.5(1.9)$ & $6.1(1.8)$ & $6.5(1.7)$ & $6.1(1.8)$ & $5.5(1.9)$ & $5.9(2.0)$ & $6.1(1.8)$ \\
\hline Boys, $n(\%)$ & $150(54.2)$ & $350(50.1)$ & $292(47.0)$ & $603(51.1)$ & $265(51.1)$ & $708(51.8)$ & $220(53.5)$ & $451(51.9)$ & $3039(51.1)$ \\
\hline Overweight, including obese, $n(\%)$, Cole 2012 & $17(6.1)$ & $152(21.8)$ & $102(16.4)$ & $170(14.4)$ & 75 (14.5) & $543(39.7)$ & 75 (18.3) & $77(8.9)$ & $1211(20.4)$ \\
\hline Mean BMI-z score at baseline (SD), Cole 2012 & $-0.09(0.9)$ & $0.40(1.2)$ & $0.24(1.1)$ & $0.19(1.1)$ & $0.11(1.1)$ & $0.97(1.2)$ & $0.37(1.0)$ & $0.08(0.9)$ & $0.37(1.2)$ \\
\hline Short sleep (<10 h/night), $n(\%)$ & $7(2.5)$ & $272(38.9)$ & $432(69.6)$ & $76(6.4)$ & $219(42.2)$ & $815(59.6)$ & $128(31.1)$ & $112(12.9)$ & $2061(34.7)$ \\
\hline High parental education, $n(\%)$ & $134(48.9)$ & $319(52.7)$ & $83(13.7)$ & $186(16.5)$ & $263(51.1)$ & $258(19.0)$ & $226(55.5)$ & $593(69.5)$ & $2062(35.9)$ \\
\hline Breakfast on weekdays, $n(\%)$ & $271(98.2)$ & $667(95.4)$ & $483(81.3)$ & 913 (77.3) & $234(46.6)$ & $1221(89.6)$ & $317(77.1)$ & 705 (94.5) & 4811 (83.4) \\
\hline Energy kcal/day on weekdays, mean (SD) & $1383(366)$ & $1421(362)$ & $1718(442)$ & $1524(439)$ & $1517(442)$ & $1697(404)$ & $1540(385)$ & $1545(401)$ & $1569(424)$ \\
\hline Mean sugar $(\mathrm{g})$, morning $(\mathrm{SD})$ & $39(22)$ & 23(13) & $23(18)$ & $48(32)$ & $33(30)$ & $26(17)$ & $34(17)$ & $28(17)$ & $32(24)$ \\
\hline Mean starch (g), morning (SD) & $25(15)$ & $38(23)$ & $17(15)$ & $28(17)$ & $27(27)$ & $19(15)$ & $18(13)$ & $26(16)$ & $25(19)$ \\
\hline Mean sugar (g), midday (SD) & $33(23)$ & $20(15)$ & $49(30)$ & $43(30)$ & $31(29)$ & $34(22)$ & $36(20)$ & $30(19)$ & $35(26)$ \\
\hline Mean starch (g), midday (SD) & $35(18)$ & $39(23)$ & $46(27)$ & $32(26)$ & $51(33)$ & $101(55)$ & $41(20)$ & $47(23)$ & $55(43)$ \\
\hline Mean sugar (g), evening (SD) & $23(19)$ & $12(12)$ & $39(26)$ & $24(22)$ & $37(26)$ & $17(16)$ & $20(14)$ & $26(19)$ & $24(21)$ \\
\hline Mean starch (g), evening (SD) & $27(19)$ & $25(20)$ & $28(20)$ & $22(16)$ & $23(19)$ & $37(36)$ & $12(12)$ & $36(19)$ & $28(25)$ \\
\hline HC sugar, morning, $n(\%)$ & $99(36)$ & $55(8)$ & $73(11)$ & $596(50)$ & $178(34)$ & $239(17)$ & $110(27)$ & $135(16)$ & $1485(25)$ \\
\hline HC starch, morning, $n(\%)$ & $60(22)$ & $334(48)$ & $77(12)$ & $403(34)$ & $172(33)$ & $186(14)$ & $42(10)$ & $212(24)$ & $1486(25)$ \\
\hline HC sugar midday, $n(\%)$ & $64(23)$ & $43(6)$ & $271(44)$ & $446(38)$ & $108(21)$ & $314(23)$ & $104(25)$ & $136(15)$ & $1486(25)$ \\
\hline HC starch midday, $n(\%)$ & $18(7)$ & $67(10)$ & $100(16)$ & $69(6)$ & $136(26)$ & $917(67)$ & $31(8)$ & $148(17)$ & $1486(25)$ \\
\hline HC sugar evening, $n(\%)$ & $79(29)$ & $42(6)$ & $322(52)$ & $307(26)$ & $261(50)$ & $193(14)$ & $363(48)$ & $234(27)$ & $1486(25)$ \\
\hline HC starch, evening, $n(\%)$ & $55(20)$ & $163(23)$ & $157(25)$ & $152(13)$ & $83(16)$ & $495(36)$ & $20(5)$ & $361(42)$ & $1486(25)$ \\
\hline
\end{tabular}

Footnote: household parental education level was categorized according to the International Standard Classification of Education (ISCED) and the original six ISCED levels [31] were
then combined into two levels (not high versus high). ISCED levels $0-4$ constitute "not high" education while levels 5 and 6 are defined as high education. Breakfast on weekdays was categorized as yes or no, based on the weekday 24-h recalls included in this study. High carbohydrate (HC-starch and HC-sugar categories) were calculated for starch and sugar at three time-points (morning, midday and evening) by assigning those in the highest quartile for grams of sugar/total energy intake (EI) and grams of starch/total EI to the HC groups. The number and percentage of children in each HC sub-category are given in the lower half of the table. 
Table 2. Cross-sectional baseline characteristics of short sleepers $(<10 \mathrm{~h})$. The right-hand columns present the regression coefficients, with $95 \%$ CI (Confidence Interval).

\begin{tabular}{|c|c|c|c|c|}
\hline Outcome & $\begin{array}{c}\text { Not Short } \\
\text { Sleeper } n=3883\end{array}$ & $\begin{array}{c}\text { Short Sleeper } \\
n=2061\end{array}$ & $\begin{array}{l}\text { Regression } \\
\text { Coefficient }\end{array}$ & $95 \% \mathrm{CI}$ \\
\hline BMI score, Cole 2012 & 0.25 & 0.61 & 0.12 & $0.05 ;-0.18$ \\
\hline \multicolumn{5}{|c|}{ Dietary factors modeled in multivariable model shown in Table 3} \\
\hline HC morning sugar, $\mathrm{n}(\%)$ & $1080(27.8)$ & 405 (19.7) & 0.03 & $-0.13 ; 0.19$ \\
\hline HC morning starch, n (\%) & $997(25.7)$ & $489(23)$ & 0.21 & $0.05 ; 0.37$ \\
\hline HC midday sugar, $\mathrm{n}(\%)$ & $987(25)$ & $499(24)$ & -0.16 & $-0.31 ;-0.00$ \\
\hline HC midday starch, $\mathrm{n}(\%)$ & $754(19)$ & $732(36)$ & -0.08 & $-0.24 ; 0.08$ \\
\hline HC evening sugar, $\mathrm{n}(\%)$ & $916(24)$ & $570(28)$ & 0.21 & $0.05 ; 0.36$ \\
\hline HC evening starch, n (\%) & $887(23)$ & $599(29)$ & 0.07 & $-0.08 ; 0.22$ \\
\hline Energy, kcal/day, mean & 1522.8 & 1655.6 & 31.74 & $7.69 ; 55.79$ \\
\hline Eats breakfast, $\%$ & 84.17 & 81.82 & -0.03 & $-0.047 ;-0.00$ \\
\hline \multicolumn{5}{|c|}{ Other factor modeled in multivariable model shown in Table 3} \\
\hline High parent education \% & 39.5 & 29.1 & -0.029 & $-0.06 ; 0.00$ \\
\hline \multicolumn{5}{|c|}{ Descriptive dietary factors, not in multivariable model shown in Table 3} \\
\hline Starch, g/day & 99.8 & 122.4 & 3.92 & $1.29 ; 6.55$ \\
\hline Sugar, g/day & 91.8 & 87.9 & 0.52 & $-1.88 ; 2.92$ \\
\hline Carbohydrate, energy- $\%$, day & $52.3 \%$ & $52.2 \%$ & 0.01 & $-0.64 ; 0.65$ \\
\hline Fat, energy- $\%$, day & $31.5 \%$ & $31.0 \%$ & 0.09 & $-0.43 ; 0.61$ \\
\hline Protein, energy- $\%$, day & $15.8 \%$ & $16.0 \%$ & -0.29 & $-0.55 ; 0.03$ \\
\hline
\end{tabular}

Footnote: High carbohydrate (HC-starch and HC-sugar categories) were calculated for starch and sugar at three time-points (morning, midday and evening) by assigning those in the highest quartile for grams of sugar/total energy intake (EI) and grams of starch/total EI to the HC groups.

Table 3. High carbohydrate intake from sugar and starch at three times of day and short sleep duration and association with BMI z-scores at baseline, adjusted for age, sex and country.

\begin{tabular}{ccc}
\hline Exposures Measured at Baseline $(\boldsymbol{n = 5 7 5 0})^{\dagger}$ & Regression Coefficient & $\mathbf{9 5 \%}$ CI \\
\hline Short sleep < 10 h versus $\geqslant 10 \mathrm{H}$ & 0.09 & $0.02 ; 0.16$ \\
Breakfast (yes v. no) & -0.28 & $-0.36 ; 0.19$ \\
HC morning sugar & -0.02 & $-0.09 ; 0.05$ \\
HC morning starch & 0.12 & $0.05 ; 0.20$ \\
HC midday sugar & 0.03 & $-0.04 ; 0.10$ \\
HC midday starch & 0.02 & $-0.07 ; 0.10$ \\
HC evening sugar & -0.04 & $-0.12 ; 0.03$ \\
HC evening starch & -0.08 & $-0.15 ;-0.00$ \\
Total energy intake in kcal & 0.03 & $0.02 ; 0.04$ \\
Parental education (high v. "not high") & -0.09 & $-0.16 ; 0.24$ \\
\hline
\end{tabular}

${ }^{\dagger} n$ reduced from 5944 at baseline due to non-response on two variables: breakfast $(n=5772)$ and Parental Education $(n=5750)$. High carbohydrate (HC-starch and HC-sugar categories) were calculated for starch and sugar at three time-points (morning, midday and evening) by assigning those in the highest quartile for grams of sugar/total energy intake (EI) and grams of starch/total EI to the HC groups. CI: Confidence Interval.

In Figure 3, the effect of short sleep duration on the relationship between HC from sugar and starch at each meal occasion and BMI z-scores is shown in a mutually adjusted model including age, sex, parental education, total EI, eating breakfast and survey country. Six interaction terms were introduced to the main effects, one of which was significant, i.e., the interaction between high starch at midday and short sleep. In children with short sleep duration, the risk posed by HC intake from starch at midday had a stronger effect in those with short sleep duration. We also observed that HC from starch in the evening among the children without short nocturnal sleep duration is inversely associated with BMI z-scores but the respective interaction term was not significant. 


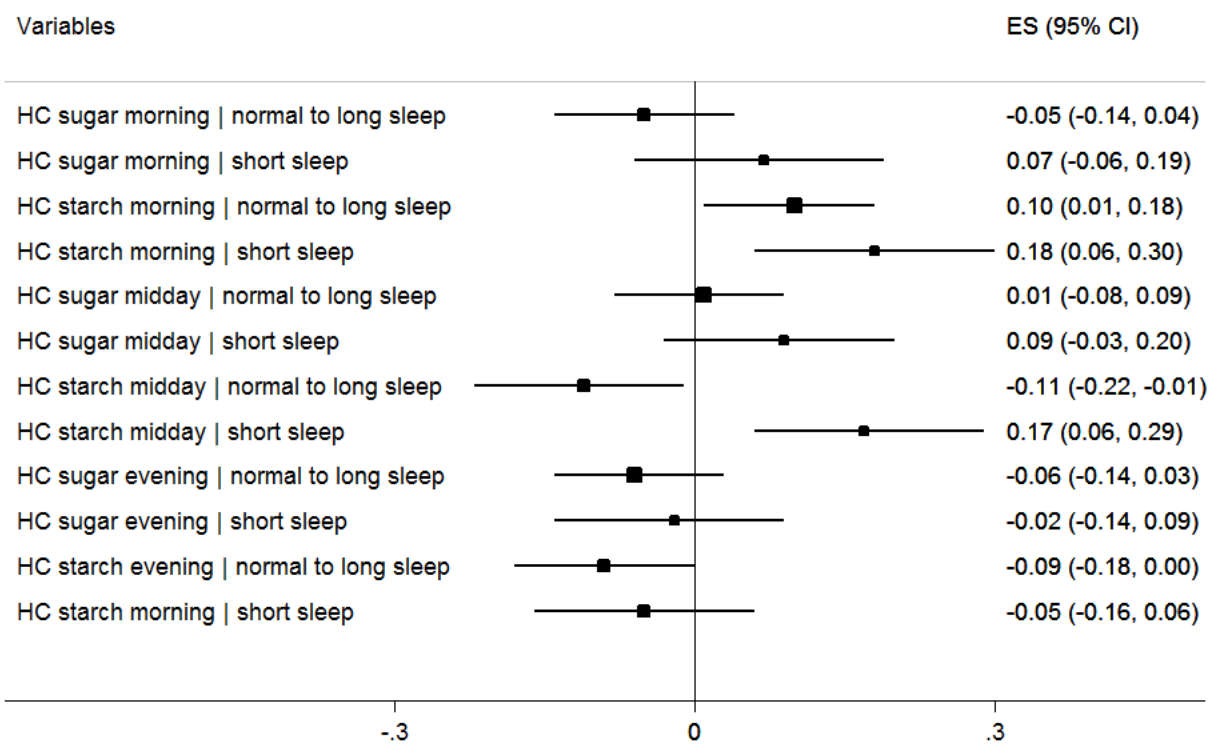

Figure 3. Effect of HC intake (sugar and starch) at 3 meal occasions on BMI z-scores at baseline by sleep duration. ES = effect size (regression coefficient). $n$ reduced from 5944 at baseline due to non-response on two variables: breakfast and parental education level $(n=5750)$; Linear regression of BMI z-scores on sleep duration, HC intake variables, and their respective product terms, further adjusted for eating breakfast, parental education, age, sex, and survey country. Long sleep represents normal and long sleep $\geqslant 10$ hours. CI: Confidence Interval.

There was a positive interaction between high midday sugar and short sleep duration with respect to BMI z-scores at two-year follow-up, but it was no longer observed after adjustment for baseline BMI z-scores (not shown). After adjustment for baseline BMI z-scores, only high parental education level remained significantly protective, (Regression coefficient $=-0.08, p=0.001$, $95 \% \mathrm{CI}=-0.12 ;-0.03$; results not shown in tables).

\section{Discussion}

Our findings demonstrate that a high proportion of carbohydrate from starch in the morning is associated with an increased risk of a higher BMI z-scores at baseline in children participating in the IDEFICS study. Moreover, we found that high intake from starch at midday, in combination with short sleep duration, poses a risk for overweight. We also showed that eating breakfast is associated with lower BMI z-scores cross-sectionally at baseline, concurring with previous research $[13,16]$ However, at the cross-sectional two-year follow-up analysis, eating breakfast offered no protection from increasing BMI z-scores, as has also been reported [17,18].

There is limited research on macronutrient distribution in children's diets. However, a systematic review of intervention studies published in 2014 examined the impact of dietary macronutrients on BMI and cardio-metabolic outcomes in overweight and obese children and adolescents [32]. From 14 eligible studies, five examined low carbohydrate intake related to BMI [32]. A meta-analysis of these low-carbohydrate studies in children and adolescents indicated a greater reduction in BMI in the low-carbohydrate group immediately after dietary intervention, but the authors noted that the quality of the studies was limited [32]. While our study was observational, our findings are in line with those of the systematic review of intervention studies, as we observed an association between HC intake from starch and higher BMI z-scores.

In adults, de Castro has reported that the time of day is an important factor influencing overall intake [33]. In the same cohort of adults, de Castro demonstrated that when the proportion of daily carbohydrate ingested in the morning was high, less total food energy and carbohydrate were consumed over the entire day [34]. In contrast, we found that high morning starch intake is 
associated with higher BMI z-scores and that breakfast-eaters consumed more total energy than those not reporting breakfast, which indicates that those skipping breakfast do not make up for skipped breakfast energy later in the day. Although de Castro did not report specifically on midday HC intake or on associations with overweight, his work may help to explain our finding that high starch intake at midday, interacting with short sleep duration, was associated with higher BMI z-scores, compared with morning carbohydrate intake. A study conducted on adults consuming a low-calorie diet studied the effects of carbohydrates consumed mostly at dinner and reported that subjects on the experimental diet underwent positive hormonal changes (leptin and adiponectin concentrations) and reported less hunger [35]. Similarly, we observed that high starch intake in the evening was inversely associated with BMI z-scores cross-sectionally at baseline. Sofer et al. [35] reported that simple dietary manipulation of carbohydrate distribution appears to yield additional benefits beyond calorie reduction. The hormone leptin regulates hunger, satiety and EI. Previous studies have reported that leptin secretion falls between 8:00 a.m. and 4:00 p.m., reaching the lowest point at 1:00 p.m., increasing at 4:00 p.m. and typically peaking at 1:00 p.m. [36,37]. This indicates that leptin levels are lowest at midday, which may be related to our findings that $\mathrm{HC}$ intake from starch in the morning and $\mathrm{HC}$ intake from starch at midday, interacting with short sleep duration, are positively associated with higher BMI z-scores.

It may be of particular interest that our cross-sectional findings are attributable to starch rather than sugar intake; there are plausible explanations for this. Most importantly, we report on all sugars, rather than added sugars, as a component of carbohydrate. The United States Department of Agriculture (USDA) recommends that children consume the following daily: two cups or approximately $350 \mathrm{~g}$ of fruit, 2.5 cups or approximately $475 \mathrm{~g}$ of vegetables, $6 \mathrm{oz}$. or approximately $168 \mathrm{~g}$ of whole grains and three cups or approximately $720 \mathrm{~mL}$ of dairy products. Following the USDA recommendations, a child exceeds $80 \mathrm{~g}$ of sugar intake when consuming just $1530 \mathrm{kcal}$ per day [38]. The mean sugar intake in our study sample was $90.5 \mathrm{~g}$, while the mean EI was $1569 \mathrm{kcal}$. This might indicate that added sugars do not contribute significantly to the dietary intake in our study population, i.e., the sugars consumed occur naturally in foods considered to be healthy. However, it is also possible that added sugars or "bad" sugars may be under-reported by parents and therefore deflate the estimate of overall sugar intake. While we have eliminated energy over- and under-reporters from our sample based on total caloric intake, we cannot exclude the existence of a "good" food-"bad" food reporting bias.

Similar to our sleep findings, previous research has demonstrated a relationship between adiposity and short sleep duration $[39,40]$. Recently, a Belgian study confirmed that short sleep duration is associated with central adiposity in children [7]. We found that those with short sleep duration $(<10 \mathrm{~h})$ had higher BMI z-scores than those with 10 or more hours of sleep. Previous research has demonstrated that acute sleep deprivation increases snack portions [41] and that lack of sleep is associated with increased snacking, an increased number of daily meals and a preference for energy-rich foods [42]. The previously-mentioned study of Malaysian children demonstrated that children who sleep less than the recommended number of hours consumed more carbohydrates and were at higher risk of overweight/obesity [10]. Our findings indicate that children with shorter sleep duration are more at risk of overweight and that inadequate sleep potentiates the association between increased BMI z-scores and HC intake. It may be speculated that a HC diet combined with inadequate sleep may represent part of the explanation for high rates of obesity in children from a lower socioeconomic position (SEP). A number of previous studies, including the IDEFICS study, have reported that children from higher-income or more educated families tend to eat more healthfully [43-47]. However, in the context of the associations reported here, it should be pointed out that our findings are statistically independent of SEP, as defined by household parental education level.

Our findings on breakfast may be of interest, in light of inconsistencies in the literature. Our cross-sectional results at baseline are in line with other European studies reporting an association 
between breakfast intake and lower BMI, compared with children who skip breakfast [13-16]. However, our findings at two-year follow-up show no consistent association between breakfast consumption and lower BMI z-scores support those of a 2010 systematic review that concluded causality has not been demonstrated [17]. Similarly, a study of Danish children aged two and five also found no association between breakfast consumption and overweight [48]. Furthermore, it might be surprising that children with short sleep duration were less likely to eat breakfast than those who slept 10 or more hours, as it might be expected that those with more waking hours would have more time to consume breakfast. While the difference was statistically significant $(82 \%:<10 \mathrm{~h}$ versus $84 \%$ : $\geqslant 10 \mathrm{~h}$ ), the absolute values were of low magnitude.

To our knowledge, this is the first study to simultaneously examine carbohydrate intake and its temporal distribution, short nocturnal sleep duration, breakfast habits and risk of overweight in a large cohort of children with diverse dietary cultures and lifestyle habits. Moreover, this study adhered to strict implementation of standardized operating procedures during fieldwork as well as plausibility checks during data entry. However, our study is not without limitations, the most important of which is including only one day of dietary recall. It is also important to note that the calculations are heterogeneous because macronutrients are calculated from a number of different FTC. For example, in Sweden, Germany and Hungary sugar was calculated as monosaccharide plus disaccharide, while in Estonia sugar consists of glucose, fructose, sucrose, maltose and lactose. These discrepancies might lead to subtle difficulties in comparing dietary carbohydrate intake. Finally, it should be kept in mind that the sample included in the IDEFICS study was not randomly selected and the related descriptive data cannot be considered to be representative at the country level.

\section{Conclusions}

This study showed BMI z-scores were cross-sectionally associated with high dietary carbohydrate intake from starch consumed in the morning, and in children with less than optimal sleep duration with high dietary carbohydrate intake from starch at midday. Breakfast consumption was not consistently associated with BMI z-scores. These findings suggest that childhood overweight might be reduced by limiting the proportion of dietary carbohydrates, particularly from starchy foods, in morning meals, and even more so in midday meals, and by encouraging the recommended amount of sleep each night.

Acknowledgments: Sources of financial support: This study was conducted as part of the IDEFICS study (http://www.idefics.edu), which was funded by the European Community within the Sixth RTD Framework Programme Contract No. 016181 (FOOD). The lead author also wishes to thank the Swedish Research Council for Health, Working Life and Welfare (http://www.forte.se/en/) for funding EPILIFE and the Stiftelsen Fru Mary von Sydows, född Wijk, Donationsfond (http://www.maryvonsydowstiftelsen.se/) for salary support. Isabelle Sioen is financially supported by the Research Foundation-Flanders (Grant No.: 1.2.683.14.N.00). The funders had no role in the design, data collection, data analysis or interpretation of data; in the writing of this manuscript; or in the decision to submit for publication. The authors are grateful for the support provided by school boards, headmasters and communities, and thank the IDEFICS children and their parents for participating in this extensive examination. The information in this document reflects the authors' views, based upon our analyses and the current literature, and is therefore provided as such.

Author Contributions: Monica Hunsberger, statistical analysis and manuscript writing; Kirsten Mehlig, statistical support and critical revisions of the manuscript; Claudia Börnhorst, statistical consulting and revisions of the manuscript; Antje Hebestreit, Luis Moreno, Toomas Veidebaum, Yiannis Kourides, Alfonso Siani, and Dénes Molnar, provided critical revisions of the manuscript; Isabelle Sioen, study design and critical revisions of the manuscript; and Lauren Lissner, study design and critical revisions of the manuscript.

Conflicts of Interest: The authors declare no conflict of interest. 


\section{References}

1. World Health Organization. Global Strategy on Diet, Physical Activity, and Health: Childhood Overweight and Obesity. 2012. Available online: http://www.who.int/dietphysicalactivity/strategy/eb11344/ strategy_english_web.pdf (accessed on 12 January 2015).

2. World Health Organization. Obesity and Overweight; Fact Sheet 311. 2014. Available online: http://www.who.int/mediacentre/factsheets/fs311/en/ (accessed on 12 January 2015).

3. Magarey, A.; Watson, J.; Golley, R.K.; Burrows, T.; Sutherland, R.; McNaughton, S.A.; Denney-Wilson, E.; Campbell, K.; Collins, C. Assessing dietary intake in children and adolescents: Considerations and recommendations for obesity research. Int. J. Pediatr. Obes. 2011, 6, 2-11. [CrossRef] [PubMed]

4. Nielsen, L.S.; Danielsen, K.V.; Sørensen, T.I. Short sleep duration as a possible cause of obesity: Critical analysis of the epidemiological evidence. Obes. Rev. 2011, 12, 78-92. [CrossRef] [PubMed]

5. Chen, X.; Beydoun, M.A.; Wang, Y. Is sleep duration associated with childhood obesity? A systematic review and meta-analysis. Obesity 2008, 16, 265-274. [CrossRef] [PubMed]

6. Hart, C.N.; Cairns, A.; Jelalian, E. Sleep and obesity in children and adolescents. Pediatr. Clin. N. Am. 2011, 58, 715-733. [CrossRef] [PubMed]

7. Michels, N.; Verbeiren, A.; Ahrens, W.; de Henauw, S.; Sioen, I. Children's sleep quality: Relation with sleep duration and adiposity. Public Health 2014, 128, 488-490. [CrossRef] [PubMed]

8. Hense, S.; Pohlabeln, H.; de Henauw, H.; Eiben, G.; Molnar, D.; Moreno, L.A.; Barba, G.; Hadjigeorgiou, C.; Veidebaum, T.; Ahrens, W. Sleep duration and overweight in European children: Is the association modified by geographic region? Sleep 2011, 34, 885-890. [CrossRef] [PubMed]

9. Accurso, A.; Bernstein, R.K.; Dahlqvist, A.; Draznin, B.; Feinman, R.D.; Fine, E.J.; Gleed, A.; Jacobs, D.B.; Larson, G.; Lustig, R.H.; et al. Dietary carbohydrate restriction in type 2 diabetes mellitus and metabolic syndrome: Time for a critical appraisal. Nutr. Metab. 2008, 5, 9. [CrossRef] [PubMed]

10. Martens, E.A.; Gonnissen, H.K.; Gatta-Cherifi, B.; Janssens, P.L.; Westerterp-Plantenga, M.S. Maintenance of energy expenditure on high-protein vs. high-carbohydrate diets at a constant body weight may prevent a positive energy balance. Clin. Nutr. 2014, 34, 968-975. [CrossRef] [PubMed]

11. Saavedra, J.M.; Deming, D.; Dattilo, A.; Reidy, K. Lessons from the Feeding Infants and Toddlers Study in North America: What Children Eat, and Implications for Obesity Prevention. Ann. Nutr. Metab. 2013, 62, S27-S36. [CrossRef] [PubMed]

12. Firouzi, S.; Poh, B.K.; Ismail, M.N.; Sadeghilar, A. Sleep habits, food intake, and physical activity levels in normal and overweight and obese Malaysian children. Obes. Res. Clin. Pract. 2014, 1, e70-e78. [CrossRef] [PubMed]

13. Fabritius, K.; Rasmussen, M. Breakfast habits and overweight in Danish schoolchildren. The role of socioeconomic positions. Ugeskr. Laeger 2008, 170, 2559-2563. [PubMed]

14. Henríquez Sánchez, P.; Doreste Alonso, J.; Laínez Sevillano, P.; Estévez González, M.D.; Iglesias Valle, M.; López Martín, G.; Sosa Iglesias, I.; Serra Majem, L. Prevalence of obesity and overweight in adolescents from Canary Islands, Spain. Relationship with breakfast and physical activity. Med. Clin. 2008, 130, 606-610. [CrossRef]

15. Dialektakou, K.D.; Vranas, P.B. Breakfast Skipping and Body Mass Index among Adolescents in Greece: Whether an Association Exists Depends on How Breakfast Skipping Is Defined. Am. Diet. Assoc. 2008, 108, 1517-1525. [CrossRef] [PubMed]

16. Mota, J.; Fidalgo, F.; Silva, R.; Ribeiro, J.C.; Santos, R.; Carvalho, J.; Santos, M.P. Relationships between physical activity, obesity and meal frequency in adolescents. Ann. Hum. Biol. 2008, 35, 1-10. [CrossRef] [PubMed]

17. Szajewska, H.; Ruszczynski, M. Systematic Review Demonstrating that Breakfast Consumption Influences Body Weight Outcomes in Children and Adolescents in Europe. Crit. Rev. Food Sci. Nutr. 2010, 50, 113-119. [CrossRef] [PubMed]

18. Brown, A.W.; Bohan-Brown, M.M.; Allison, D.B. Belief beyond the evidence: Using the proposed effect of breakfast on obesity to show 2 practices that distort scientific evidence. Am. J. Clin. Nutr. 2013, 98, 1298-1308. [CrossRef] [PubMed] 
19. Ahrens, W.; Bammann, K.; de Henauw, S.; Halford, J.; Palou, A.; Pigeot, I.; Siani, A.; Sjöström, M. European Consortium of the IDEFICS Project. Understanding and preventing childhood obesity and related disorders-IDEFICS: A European multilevel epidemiological approach. Nutr. Metab. Cardiovasc. Dis. 2006, 16, 302-308. [CrossRef] [PubMed]

20. Ahrens, W.; Bammann, K.; Siani, A.; Buchecker, K.; de Henauw, S.; Iacoviello, L.; Hebestreit, A.; Krogh, V.; Lissner, L.; Mårild, S.; et al. IDEFICS Consortium. The IDEFICS cohort: Design, participation, socio-demographic characteristics and participation in the baseline survey. Int. J. Obes. 2011, 35, S3-S15. [CrossRef] [PubMed]

21. Bammann, K.; Peplies, J.; Sjöström, M.; Lissner, L.; de Henauw, S.; Galli, C.; Iacoviello, L.; Krogh, V.; Mårild, S.; Pigeot, I.; et al. Assessment of diet, physical activity and biological, social and environmental factors in a multi-centre European project on diet- and lifestyle-related disorders in children (IDEFICS). Public Health 2006, 14, 279-289. [CrossRef]

22. Vereecken, C.A.; Covents, M.; Sichert-Hellert, W.; Alvira, J.M.; le Donne, C.; de Henauw, S.; de Vriendt, T.; Phillipp, M.K.; Béghin, L.; Manios, Y.; et al. Development and evaluation of a self-administered computerized 24-h dietary recall method for adolescents in Europe. Int. J. Obes. 2008, 32, 26-34. [CrossRef] [PubMed]

23. Hebestreit, A.; Börnhorst, C.; Barba, G.; Siani, A.; Huybrechts, I.; Tognon, G.; Eiben, G.; Moreno, L.A.; Fernández Alvira, J.M.; Loit, H.M.; et al. Associations between energy intake, daily food intake and energy density of foods and BMI z-score in 2-9-year-old European children. Eur. J. Nutr. 2014, 53, 673-681. [PubMed]

24. Food Standard Agency; Public Health of England. McCance and Widdowson's the Composition of Foods, 5th ed.; Cambridge: Royal Society of Chemistry: Cambridge, UK, 1992.

25. National Heart Lung Blood Institute. How Much Sleep Is Enough? Available online: http:/ / www.nhlbi.nih.gov/health/health-topics/topics/sdd/howmuch (accessed on 8 March 2015).

26. Svensson, Å.; Larsson, C.; Eiben, G.; Lanfer, A.; Pala, V.; Hebestreit, A.; Huybrechts, I.; Fernández-Alvira, J.M.; Russo, P.; Koni, A.C. European children's sugar intake on weekdays versus weekends: The IDEFICS study. Eur. J. Clin. Nutr. 2014, 68, 822-828. [CrossRef] [PubMed]

27. Schofield, W.N. Predicting basal metabolic rate, new standards and review of previous work. Hum. Nutr. Clin. Nutr. 1985, 39, S5-S41.

28. Goldberg, G.R.; Black, A.E.; Jebb, S.A.; Cole, T.J.; Murgatroyd, P.R.; Coward, W.A.; Prentice, A.M. Critical evaluation of energy intake data using fundamental principles of energy physiology: 1. Derivation of cut-off limits to identify under-recording. Eur. J. Clin. Nutr. 1991, 45, 569-581. [PubMed]

29. Cole, T.J.; Lobstein, T. Extended international (IOTF) body mass index cut-offs for thinness, overweight and obesity. Pediatr. Obes. 2012, 7, 284-294. [CrossRef] [PubMed]

30. Stomfai, S.; Ahrens, W.; Bammann, K.; Kovács, E.; Mårild, S.; Michels, N.; Moreno, L.A.; Pohlabeln, H.; Siani, A.; Tornaritis, M. Intra- and inter-observer reliability in anthropometric measurements in children. Int. J. Obes. 2011, 35, S45-S51. [CrossRef] [PubMed]

31. UNESCO. International Standard Classification of Education. 2010. Available online: http:/ / www.uis.unesco.org (accessed on 14 December 2014).

32. Gow, M.L.; Ho, M.; Burrows, T.L.; Baur, L.A.; Stewart, L.; Hutchesson, M.J.; Cowell, C.T.; Collins, C.E.; Garnett, S.P. Impact of dietary macronutrient distribution on BMI and cardiometabolic outcomes in overweight and obese children and adolescents: A systematic review. Nutr. Rev. 2014, 72, 453-470. [CrossRef] [PubMed]

33. De Castro, J. The time of day of food intake influences overall intake in humans. J. Nutr. 2004, 134, $104-111$. [PubMed]

34. De Castro, J. The time of day and the proportions of macronutrients eaten are related to daily food intake. Br. J. Nutr. 2007, 98, 1077-1083. [CrossRef] [PubMed]

35. Sofer, S.; Eliraz, A.; Kaplan, S.; Voet, H.; Fink, G.; Kima, T.; Madar, Z. Greater Weight Loss and Hormonal Changes After 6 Months Diet With Carbohydrates Eaten Mostly at Dinner. Obesity 2011, 19, 2006-2014. [CrossRef] [PubMed]

36. Coleman, R.A.; Herrmann, T.S. Nutritional regulation of leptin in humans. Diabetologia 1999, 42, 639-646. [CrossRef] [PubMed] 
37. Yildiz, B.O.; Suchard, M.A.; Wong, M.L.; McCann, S.M.; Licinio, J. Alterations in the dynamics of circulating ghrelin, adiponectin, and leptin in human obesity. Proc. Natl. Acad. Sci. USA 2004, 101, 10434-10439. [CrossRef] [PubMed]

38. United States Department of Agriculture. Online Diet Assessment Tool. Available online: http:/ / www.supertracker.usda.gov/ foodtracker (accessed on 7 April 2015).

39. Patel, S.R.; Hu, F.B. Short sleep duration and weight gain: A systematic review. Obesity 2008, 3, $643-653$. [CrossRef] [PubMed]

40. Beccuti, G.; Pannain, S. Sleep and obesity. Curr. Opin. Clin. Nutr. Metab. Care 2011, 14, 402-412. [CrossRef] [PubMed]

41. Hogenkamp, P.S.; Nilsson, E.; Nilsson, V.C.; Chapman, C.D.; Vogel, H.; Lundberg, L.S.; Zarei, S.; Cedernaes, J.; Rångtell, F.H.; Broman, J.E.; et al. Acute sleep deprivation increases portion size and affects food choice in young men. Psychoneuroendocrinology 2013, 38, 1668-1674. [CrossRef] [PubMed]

42. Chaput, J.P. Sleep patterns, diet quality and energy balance. Physiol. Behav. 2014, 134, 86-91. [CrossRef] [PubMed]

43. Fernández-Alvira, J.M.; Mouratidou, T.; Bammann, K.; Hebestreit, A.; Barba, G.; Sieri, S.; Reisch, L.; Eiben, G.; Hadjigeorgiou, C.; Kovacs, E. Parental education and frequency of food consumption in European children: The IDEFICS study. Public Health Nutr. 2012, 16, 487-498. [CrossRef] [PubMed]

44. Abudayya, A.H.; Stigum, H.; Shi, Z.; Abed, Y.; Holmboe-Ottesen, G. Socio-demographic correlates of food habits among school adolescents (12-15 years) in North Gaza Strip. BMC Public Health 2009, 9, 185. [CrossRef] [PubMed]

45. Sandvik, C.; Gjestad, R.; Samdal, O.; Brug, J.; Klepp, K.I. Does socioeconomic status moderate the associations between psychosocial predictors and fruit intake in schoolchildren? The Pro Children study. Health Educ. Res. 2010, 25, 121-134. [CrossRef] [PubMed]

46. Suliga, E. Parental education and living environmental influence on physical development, nutritional habits as well as level of physical activity in Polish children and adolescents. Anthropol. Anz. 2010, 68, 53-66. [CrossRef] [PubMed]

47. Blake, C.E.; Wethington, E.; Farrell, T.J.; Bisogni, C.A.; Devine, C.M. Behavioral contexts, food-choice coping strategies, and dietary quality of a multiethnic sample of employed parents. J. Am. Diet. Assoc. 2011, 111, 401-407. [CrossRef] [PubMed]

48. Küpers, L.K.; de Pijper, J.J.; Sauer, P.J.J.; Stolk, R.P.; Corpeleijn, E. Skipping breakfast and overweight in two and five year old Dutch children-GECKO Drenthe cohort. Int. J. Obes. 2014, 38, 569-571. [CrossRef] [PubMed]

(C) 2015 by the authors; licensee MDPI, Basel, Switzerland. This article is an open access article distributed under the terms and conditions of the Creative Commons by Attribution (CC-BY) license (http:/ / creativecommons.org/licenses/by/4.0/). 